\section{Joël Nargeot Pierre Charnet}

\title{
Diversité moléculaire des canaux calciques : du gène à la fonction
}

Les ions calcium sont impliqués dans le développement et le contrôle de nombreuses fonctions cellulaires allant du couplage excitation-contraction musculaire, à la libération d'hormones ou de neurotransmetteurs, à l'activation d'enzymes ou à l'expression de certains gènes. L'entrée rapide de calcium dans les cellules excitables est réglée principalement par des macromolécules de la membrane plasmique, les canaux calciques dépendants du potentiel, qui constituent une classe hétérogène de protéines sensibles aux variations du potentiel membranaire. Les travaux d'identification et de caractérisation de plusieurs types de canaux calciques ont révélé leur grande diversité et permettent de mieux comprendre comment les cellules utilisent le signal calcique pour contrôler des fonctions physiologiques très variées. Les canaux calciques neuronaux qui semblent impliqués dans plusieurs maladies représentent des cibles pharmacologiques nouvelles.

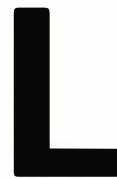

ion calcium $\left(\mathrm{Ca}^{2+}\right)$ est un second messager ubiquitaire et un régulateur de très nombreuses fonctions métaboliques. Sa concentration intracellulaire $\left[\mathrm{Ca}^{2+}\right]_{i}$ au repos est maintenue très basse (de l'ordre de $0,1 \mu \mathrm{M})$ et va s'élever de façon transitoire lors de dépolarisations membranaires qui provoquent l'ouverture de pores très sélectifs nommés "canaux calciques". Toute altération de l'homéostasie calcique et en particulier l'élévation durable de $\left[\mathrm{Ca}^{2+}\right] \mathrm{i}$ va engendrer en retour des situations pathologiques pouvant aller jusqu'à la mort cellulaire. L'étude des bases moléculaires de la diversité des canaux calciques représente une étape essentielle dans la compréhension des physiopathologies liées à des modifications de l'homéostasie calcique et le développement in fine de nouveaux agents pharmacologiques ayant une plus grande spécificité tissulaire. Dans le contexte actuel, la recherche d'antagonistes de canaux calciques neuronaux paraît une voie très prometteuse pour la prévention ou le traitement d'affections neurologiques dégénératives ou aiguës, comme l'ischémie cérébrale.

\section{Diversité fonctionnelle} des canaux calciques

L'électrophysiologie cellulaire permet une approche fonctionnelle de l'activité des canaux calciques par la 


\section{RÉFÉRENCES}

1. Rougier O, Vassort G, Garnier D, Gargouil M, Corabouf E. Existence and role of a slow inward current during the frog atrial potential. Pflügers Arch 1969; 308 : 91110 .

2. Hamill OP, Marty A, Neher E Sackmann B, Sigworth FJ. Improved patch clamp technique for high resolution current recording from cells and cell free membrane patches. Pflügers Arch 1981 ; 391 : 85-100.

3. Tsien RW, Ellinor PT, Horne WA. Molecular diversity of voltage-dependent $\mathrm{Ca}^{2+}$ channels. Trends Physiol Sci 1991 ; 12 : 34954.

4. Wheeler DB, Randall A, Tsien RW. Roles of N-type and Q-type $\mathrm{Ca}^{2+}$ channels in supporting hippocampal synaptic transmission. Science 1994; 264 : 107-11.

5. Westenbroek E, Hell JW, Warner C, Dubel SJ, Snutch TP, Catterall WA. Biochemical properties and subcellular distribution of an N-type calcium channel $\alpha 1$ subunit. Neuron 1992 ; 9 : 1099-115.

6. Turner JT, Adams ME, Dunlap K Calcium channels coupled to glutamate release identified by omega-Aga-IVA. Science $1992 ; 258: 310-3$.

7. Takahashi T, Momiyama A. Different types of calcium channels mediate central synaptic transmission. Nature 1993 ; 366 : 156-8.

8. Uchitel OD, Protti DA, Sanchez V, Cherskey BD, Sugimori M, Llinas R. P-type voltage-dependent calcium channel mediates presynaptic calcium influx and transmitter release in mammalian synapses. Proc Natl Acad Sci USA 1992; 89 : 3330-3.

9. Mintz IM, Adams ME, Bean BP. P-type calcium channels in rat central and peripheral neurons. Neuron 1992 ; 9 : 85-95.

10. Neveu D, Nargeot J, Richard S. Two high-voltage-activated, dihydropyridine-sensitive $\mathrm{Ca}^{2+}$ channel currents with distinct electrophysiological and pharmacological properties in cultured aortic myocytes mesure directe du courant transmembranaire transporté par les ions $\mathrm{Ca}^{2+}$. La mise en évidence d'un courant calcique activé lors de la dépolarisation de la membrane dit "courant lent ", et de son rôle au niveau du couplage excitation-contraction a été réalisée par des mesures en potentiel imposé sur des trabécules multicellulaires cardiaques il y a plus de vingt ans, en particulier par l'utilisation de la technique dite de "double partition de saccharose "[1]. Cependant il a fallu attendre le développement de la technique du patch clamp [2] pour mesurer le courant transitant au niveau d'une cellule isolée ou d'un canal unique (figure 1), et introduire le concept de diversité des canaux calciques. Cette technique a permis aussi la caractérisation des canaux calciques du système nerveux central et de nombreuses cellules, excitables et non excitables, jusqu'alors pratiquement inaccessibles aux mesures en voltage imposé.

La première classification des canaux calciques a été fondée sur des critères électrophysiologiques auxquels se sont rapidement associés des critères pharmacologiques après la découverte de toxines spécifiques (pour revue [3]). On peut distinguer deux principales catégories de canaux calciques en fonction de leur seuil d'activation. La première catégorie s'active pour de faibles dépolarisations, s'inactive rapidement d'une manière dépendante du voltage, a une petite conductance élémentaire et une perméablité équivalente pour le calcium et le baryum. Ce sont les LVA (low voltage activated) ou T (transient) pour lesquels il n'a pas été décrit, à l'heure actuelle, de ligand vraiment spécifique. La seconde catégorie est activée par des dépolarisations plus élevées $(>-30 \mathrm{mV})$ et engendre des courants qui s'inactivent peu, ou beaucoup plus lentement. Ce sont des canaux calciques de type haut seuil ou HVA (pour high voltage activated). L'existence de plusieurs types de HVA a ensuite été démontrée. Il s'agit tout d'abord du type L (pour long lasting) qui a une inactivation très lente, une conductance élémentaire plus grande et une perméabilité pour les ions $\mathrm{Ba}^{2+}$ généralement plus élevée que celle pour les ions
$\mathrm{Ca}^{2+}$. La caractéristique essentielle du type L est sa sensibilité aux " antagonistes calciques " et, en particulier, à la classe des dihydropyridines, outils pharmacologiques très précieux, comprenant à la fois des antagonistes (nifédipine) utilisés en thérapeutique cardiovasculaire et des agonistes (Bay K 8644). D'autres courants de type haut seuil ont ensuite été décrits sur les cellules nerveuses ; on les distingue essentiellement sur des critères pharmacologiques mais ils diffèrent aussi par leur dépendance du potentiel et par leur cinétique. Le type $\mathrm{N}$ est spécifiquement bloqué par une toxine peptidique isolée d'un escargot marin

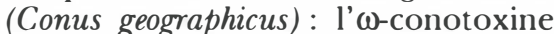
GVIA ( $\omega$-CgT-GVIA). Le type P est bloqué par le venin d'une araignée (Agelenopsis aperta) et plus précisément une polyamine (la FTX) et une fraction peptidique (l' $\omega$-AgaIVA) contenues dans ce venin. Le type $\mathrm{Q}$ qui s'apparente au type $\mathrm{P}$, a une certaine sensibilité à l'w-Aga-IVA mais est bloqué beaucoup plus spécifiquement par une autre toxine extraite de Conus magus: l' $\omega$-conotoxine MVIIC ( $\omega$-CmT-MVIIC) [4]. Les Tableaux $I$ et $I I$ résument les caractéristiques fonctionnelles principales, biophysiques et pharmacologiques, des divers types de canaux calciques.

Les canaux de type $\mathrm{T}$ et $\mathrm{L}$ sont retrouvés sur la plupart des cellules excitables, où ils sont souvent coexprimés. La fonction physiologique du type $T$ reste méconnue mais il est probable, étant données sa gamme d'activation et sa cinétique, qu'il soit impliqué dans la génération d'activités répétitives de type pacemaker. Le type L correspond au courant lent décrit à l'origine sur les préparations musculaires et joue un rôle majeur dans les couplages excitationcontraction et excitation-sécrétion. Sa modulation par les classes "d'antagonistes calciques " existantes a des implications thérapeutiques importantes dans le cadre des maladies cardiovasculaires. Le type $\mathrm{N}$ est distribué sur un grand nombre de neurones centraux ou périphériques, notamment au niveau présynaptique [5]. C'est aussi le cas du type $\mathrm{P}$ qui est, cependant, très fortement exprimé au niveau des cellules de Purkinje du cervelet. L'utilisation 


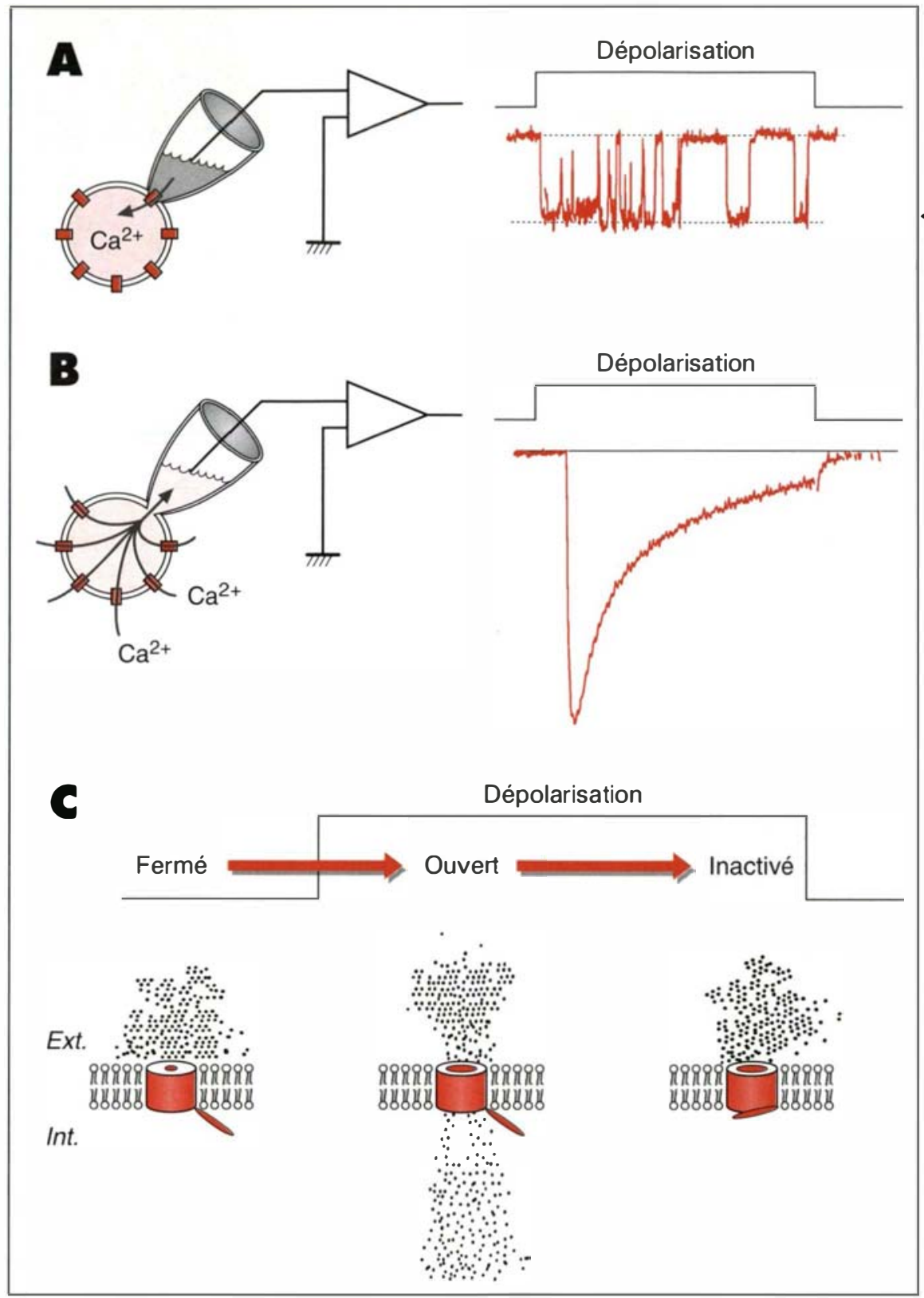

des toxines spécifiques comme l' $\omega$ CgT-GVIA ou l' $\omega$-Aga-IVA a permis de démontrer l'implication de chacun d'entre eux au niveau de la libération de neurotransmetteurs comme le glutamate dans le système nerveux central $[6,7]$. Le type $P$ aurait de plus un rôle important à la jonction neuromusculaire de mammifère où il contrôlerait la libération d'acétylcholine [8]. Enfin, le type Q, décrit plus récemment au niveau des cellules granulaires du cervelet, serait responsable, en association avec le type $\mathrm{N}$, de la transmission $\mathrm{m} / \mathrm{s} n^{\circ} 12$, vol. 10 , décembre 94
Figure 1. Enregistrement de l'activité électrique d'une cellule ou d'un canal. La technique électrophysiologique la plus utilisée aujourd'hui est celle du patch clamp mise au point par Neher et Sackmann. Elle consiste à appliquer une pipette de verre (généralement en borosilicate) de faible diamètre (1-5 $\mu \mathrm{m})$ sur la surface de la membrane de la cellule et à créer une faible dépression à l'intérieur de cette pipette. Cela permet d'aspirer légèrement la membrane de la cellule se trouvant sous la pipette et d'établir un contact électrique de très forte résistance (plusieurs gigaohms). On peut de cette manière enregistrer le courant de très faible amplitude (proche du picoampèrel qui s'écoule à travers un canal unique isolé dans la portion de membrane à l'extrémité de la pipette. Cette configuration est dite cellule attachée (A). Une succion plus forte appliquée à la membrane induit la rupture de la portion de membrane à l'extrémité de la pipette et met en communication les milieux intrapipette et intracellulaire. Cela permet d'enregistrer l'activité électrique de l'ensemble de la membrane cellulaire, c'est-à-dire le courant à travers l'ensemble des canaux. Cette configuration est dite cellule entière (B). Une dépolarisation à partir du potentiel de repos de la cellule ( - $80 \mathrm{mV}$ ) vers un potentiel proche du plateau d'un potentiel d'action $(\sim+10 \mathrm{mV})$, induit l'ouverture transitoire des canaux calciques et une entrée d'ion calcium qui diminue ensuite en fonction du temps (par convention, le courant entrant de cations est dirigé vers le bas). La dépolarisation induit un changement de conformation de la protéine dû au mouvement d'éléments chargés au niveau des segments $S 4$ constituant le voltage sensor (voir figure 3) qui aboutit à la formation d'un pore sélectif pour le calcium (activation). Elle provoque aussi, avec une cinétique plus lente, le mouvement d'une structure située sur la face interne de la protéine qui va bloquer progressivement le flux d'ions par un mécanisme encore inconnu (inactivation) (C). 
Tableau 1

PROPRIÉTÉS BIOPHYSIQUES DES CANAUX CALCIQUES

\begin{tabular}{|c|c|c|c|c|}
\hline \multicolumn{5}{|c|}{ PROPRIÉTÉS BIOPHYSIQUES DES CANAUX CALCIQUES } \\
\hline Type & Nomenclature & Activation & Inactivation & Conductance \\
\hline $\begin{array}{l}T \\
L \\
N \\
P \\
Q\end{array}$ & $\begin{array}{l}\text { Transient } \\
\text { Long-lasting } \\
\text { Neuronal } \\
\text { Purkinje } \\
\text { Q après P }\end{array}$ & $\begin{array}{l}\text { bas seuil (environ - } 70 \mathrm{mV} \text { ) } \\
\text { haut seuil (environ }-20 \mathrm{mV} \text { ) } \\
\text { haut seuil (environ }-30 \mathrm{mV} \text { ) } \\
\text { intermédiaire (environ }-60 \mathrm{mV} \text { ) } \\
\text { haut seuil (environ }-30 \mathrm{mV} \text { ) }\end{array}$ & $\begin{array}{l}\text { rapide } \\
\text { lente } \\
\text { intermédiaire } \\
\text { lente } \\
\text { intermédiaire }\end{array}$ & $\begin{array}{l}8 p S \\
20-25 p S \\
10-20 p S \\
10-12 p S \\
-\end{array}$ \\
\hline
\end{tabular}

Tableau II

\section{RÉFÉRENCES}

11. Forti L, Pietrobon D. Functional diversity of L-type calcium channels in rat cerebellar neurons. Neuron $1993 ; 10: 437-50$.

12. Tiaho F, Nargeot J, Richard S. Voltagedependent regulation of L-type cardiac Ca channels by isoproterenol. Pflügers Arch $1991 ; 419: 596-602$.

13. Sculptoreanu A, Rotman E, Takahashi M, Scheuer T, Catterall WA. Voltage-dependent potentiation of the activity of cardiac L-type calcium channel alpha-1 subunits due to phosphorylation by cAMPdependent protein kinase. Proc Natl Acad Sci USA 1993 ; 90 : 10135-9.

14. Neveu D, Quignard JF, Fernandez A, Richard S, Nargeot I. Differential $\beta$-adrenergic regulation and phenotypic modulation of voltage-gated calcium currents in rat aortic myocytes. J Physiol (London) 1994 (sous presse).

15. Mogul DJ, Adams ME, Fox AP. Differential activation of adenosine receptors decreases $\mathrm{N}$-type but potentiates $\mathrm{P}$-type $\mathrm{Ca}^{2+}$ current in hippocampal CA3 neurons. Neu ron $1993 ; 10: 327-34$

16. Lacerda AE, Rampe D, Brown AM. Effects of protein kinase $\mathrm{C}$ activators on cardiac $\mathrm{Ca}^{2+}$ channels. Nature $1988 ; 335$ 249-51.

17. Swartz KJ. Modulation of $\mathrm{Ca}$ channels by protein kinase $\mathrm{C}$ in rat central and peripheral neurons : disruption of $G$ proteinmediated inhibition. Neuron 1993 ; 11 : 30520.

18. Lory P, Nargeot J. Cyclic AMP-dependent modulation of cardiac calcium channels expressed in Xenopus laevis oocytes. Biochem Biophys Res Commun 1992 ; 182 : 1059-65.

19. Bourinet E, Fournier F, Lory P, Charnet $P$, Nargeot J. PKC regulation of cardiac calcium channels expressed in Xenopes oocytes. Pflügers Arch 1992 ; 921 : 247-55.

20. Mc Carron JG, Mc Geown JG, Reardon S, Ikebe M, Fag FS, Walsh JV. Calcium dependent enhancement of calcium current in smooth muscle by calmodulindependent protein kinase II. Nature 1992 ;

PHARMACOLOGIE DES INHIBITEURS DES CANAUX CALCIQUES

\begin{tabular}{|l|l|l|l|l|l|}
\hline Type & Dihydropyridine & $\omega-C g T-G V I A$ & $\omega$-Aga-IVA & $\omega-C m T-M V I I C$ & $\begin{array}{c}\text { lons } \\
\text { divalents }\end{array}$ \\
\hline $\mathrm{T}$ & +- & - & - & - & $\mathrm{Ni}>\mathrm{Cd}$ \\
$\mathrm{L}$ & ++ & +- & - & - & $\mathrm{Cd}>\mathrm{Ni}$ \\
$\mathrm{N}$ & - & ++ & - & + & $\mathrm{Cd}>\mathrm{Ni}$ \\
$\mathrm{P}$ & - & - & ++ & + & $?$ \\
$\mathrm{Q}$ & - & - & +- & ++ & $?$ \\
\hline
\end{tabular}

Ni : nickel; Cd : cadmium.

dines. Il est bien connu, par exemple, que le courant calcique de type $\mathrm{L}$ musculaire a une cinétique très lente par rapport à celle du courant calcique cardiaque. Une diversité fonctionnelle au sein des canaux de type $L$ a aussi été décrite au niveau des cellules vasculaires [10] et dans les neurones du cervelet [11].

\section{Régulation des canaux calciques par les phosphorylations et les protéines $G$}

Les neurotransmetteurs et hormones constituent des stimuli essentiels pouvant régler l'activité des canaux calciques. Les régulations les mieux connues sont, d'une part, les phosphorylations qui impliquent diverses protéine-kinases et, d'autre part, celles réalisées par des protéines de couplage ou protéines G. Les protéine-kinases sont généralement activées par des seconds messagers intracellulaires, eux mêmes sous la dépendance de récepteurs extracellulaires qui exercent ainsi une régulation indirecte de l'activité des canaux calciques. Cette voie de régulation est bien connue pour les canaux de type L cardiaques. En effet, la stimulation $\beta$-adrénergique, qui conduit à un effet inotrope positif, stimule l'adénylyl cyclase par l'intermédiaire d'une protéine Gs, et induit une augmentation de l'AMPc intracellulaire qui va activer la protéine kinase A (PKA). La PKA, en phosphorylant le canal calcique ou une protéine étroitement associée, augmente la probabilité d'ouverture du canal et donc l'influx calcique. Les divers récepteurs présents sur les cellules cardiaques, et qui sont couplés positivement à l'adénylyl cyclase, conduisent au même résultat. Nous avons montré récemment que cette stimulation du canal calcique dépend du potentiel de la membrane, l'action de l'isoprotérénol étant beaucoup plus marquée lorsque le potentiel de membrane est maintenu très négatif [12]. Les cellules les plus polarisées, comme les cellules ventriculaires, devraient, de ce fait, être les plus affectées par la stimulation $\beta$-adrénergique. Les canaux $\mathrm{L}$ musculaires squelettiques sont aussi réglés par la PKA, et il a été montré très récemment que la "facilitation " du courant calcique observée lors de stimulations répétitives, requiert une étape de phosphorylation par la PKA. Ce processus aurait une grande importance dans la modulation de la 
contraction musculaire en réponse à des stimuli tétaniques [13]. Sur les cellules vasculaires, le courant calcique de type $\mathrm{L}$ est généralement insensible à l'AMPc intracellulaire. Cependant, deux courants de type haut seuil sensibles aux DHP ont été récemment décrits sur des myocytes artériels en culture, l'un d'entre eux étant potentialisé par l'AMPc [14]. L'AMPc pourrait également augmenter le courant de type $P$ sur les neurones d'hippocampe [15]. La stimulation de la protéine kinase $\mathrm{C}$ induit aussi une augmention du courant calcique cardiaque de type $\mathrm{L}$ [16] ainsi que les courants calciques de divers neurones, centraux ou périphériques [17]. Les effets des protéine kinases $\mathrm{A}$ et $\mathrm{C}$ ont aussi été étudiés sur des canaux calciques exprimés à partir d'ARN tissulaire dans des ovocytes de xénope. L'injection d'ARN de cœur de rat conduit à l'expression de canaux de type L, stimulés à la fois par la PKA et la PKC $[18,19]$. Une potentialisation des canaux calciques $\mathrm{L}$ vascu-

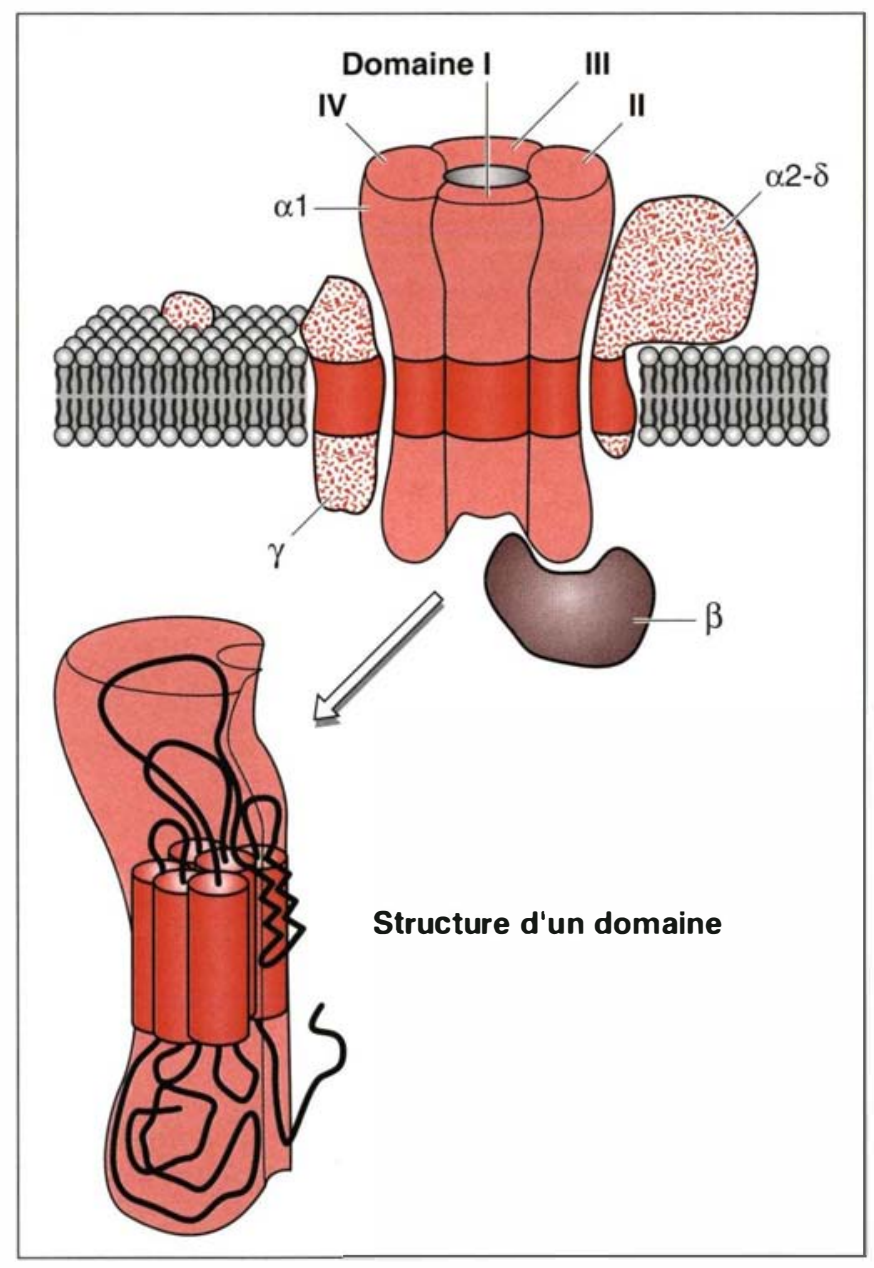

Figure 2. Structure schématique du canal calcique squelettique de type $L$. Le canal calcique est composé de quatre sous-unités dont trois $1 \alpha 1, \alpha 2-\delta$ et $\gamma)$ sont transmembranaires, la sous-unité $\beta$ étant cytoplasmique. La sousunité $\alpha 1$, qui forme le canal proprement dit, est composée de quatre domaines ayant chacun six segments en hélice $\alpha$ transmembranaire, nommés S1 à S6. La région du pore du canal où s'effectue la sélectivité entre les ions calcium et sodium est due à un double feuillet $\beta$ antiparallèle se trouvant entre les segments S5 et S6 de chaque domaine (voir figure 3).

$\mathrm{m} / \mathrm{s} n^{\circ} 12$, vol. 10 , decembre 94 laires par la calmoduline kinase II a été décrite [20]. A l'heure actuelle, la régulation des canaux calciques neuronaux par les diverses kinases est encore mal connue en raison de la difficulté de séparer précisément les divers types de courants.

Une modulation des canaux calciques par les protéines $G$ a été décrite depuis quelques années et concerne principalement les canaux neuronaux de type N. Cette modulation est toujours dans le sens d'une inhibition. De nombreux neurotransmetteurs ou hormones peptidiques inhibent les canaux $\mathrm{N}$ de divers neurones via une protéine de type Go, sensible à la toxine de pertussis. C'est le cas, entre autres, de la noradrénaline, de l'acide $\gamma$-aminobutyrique (GABA), de la substance $P$, ou de la somatostatine [21]. Ce type de régulation n'est pas exclusivement observé avec le type N. Sur les cellules pituitaires de rat, en utilisant des anticorps anti-peptides dirigés contre plusieurs types de protéines $G$, on a mis en évidence l'inhibition de canaux calciques de type $\mathrm{L}$ et $\mathrm{T}$ par le récepteur dopaminergique D2 et par l'intermédiaire d'une protéine Go [22]. Au niveau du cervelet, c'est un canal de type $P$ qui a été décrit comme inhibé par le $\mathrm{GABA}_{\mathrm{B}}$, par l'intermédiaire d'une protéine $G$ [23]. La régulation des canaux calciques neuronaux par des protéines $G$ est donc un mécanisme physiologique fondamental, mais la nature exacte des processus moléculaires permettant l'interaction entre le canal et la protéine $G$ sont encore mal connus. L'hypothèse la plus récemment proposée est une altération de la perméabilité des ions calcium [24].

\section{Structure protéique des canaux calciques. Composition en sous- unités}

L'étape biochimique a été essentielle pour l'analyse structurale des canaux calciques. Elle a pu être réalisée grâce à la découverte de ligands spécifiques, en particulier les dihydropyridines (DHP), qui, radiomarquées, ont permis d'identifier des sites récepteurs à forte affinité dans les tubules transverses de muscle squelettique [25]. Le récepteur des DHP 


\section{RÉFÉRENCES}

21. Bockaert J. Les protéines $G$ étendent leur pouvoir sur les canaux ioniques. médecine/sciences $1989 ; 5$ : $562-9$.

22. Lledo PM, Homburger V, Bockaert J, Vincent ID. Differential $G$ protein-mediated coupling of D2 dopamine receptors to $\mathrm{K}^{+}$and $\mathrm{Ca}^{2+}$ currents in rat anterior pituitary cells. Neuron $1992 ; 8,455-63$.

23. Mintz IM, Bean BP. GABA-B receptor inhibition of P-type Ca2+ channels in central neurons. Neuron $1993 ; 10: 889-98$.

24. Kuo CC, Bean BG. G-protein modulation of ion permeation through $\mathrm{N}$-type calcium channels. Nature $1993 ; 365: 258-62$.

25. Fosset M, Jaimovich E, Delpont E, Lazdunski M. $\left.{ }^{3} \mathrm{H}\right]$ nitrendipine receptors in skeletal muscle. I Biol Chem 1983; 258 : skeletal

26. Campbell KP, Leung AT, Sharp AH. The biochemistry and molecular biology of the dihydropyridine-sensitive calcium channel. Trends Neurosi 1988 ; 11 : 425-30.

27. Witcher DR, De Waard M, Sakamoto J, Franzini-Armstrong C, Pragnell M, Kahi SD, Campbell KP. Subunit identification and reconstitution of the N-type $\mathrm{Ca}^{2+}$ channel complex purified from brain. Science $1993 ; 262: 486-9$

28. Sakamoto J, Campbell KP. A monoclonal antibody to the $\beta$ subunit of the skeletal muscle dihydropyridine receptor immunoprecipitates the brain $\omega$-conotoxin GVIA receptor. J Biol Chem 1991 ; 266 : 189149.

29. Tanabe T, Tkeshima $\mathrm{H}$, Mikami A, Flockerzi V, Takahashi H, Kangawa K, Kojima $M$, Matsuo $H$, Hirose $T$, Numa $S$. Primary structure of the receptor for calcium channel blockers from skeletal muscle. Nature 1987 ; 328 : 313-8.

30. Nargeot J, Dascal N, Lester HA. Heterologous expression of calcium channels. $I$ Membrane Biol 1992 ; 126 : 97-108.

31. Snutch TP, Reiner PB. $\mathrm{Ca}^{2+}$ channels diversity of form and function. Curr Opin Neurobiol $1992 ; 2$ : 247-53.

32. Dascal N, Snutch TP, Lubbert H, Davidson N, Lester HA. Expression and modulation of voltage-gated calcium channels after RNA injection in Xenopus oocytes. Science a été purifié à partir du muscle squelettique; il est constitué de cinq sous-unités : une sous-unité $\alpha$ l $(175 \mathrm{kDa})$, responsable de la formation du canal et des sites récepteurs des grandes familles d'antagonistes calciques (DHP, phénylalkylamines, benzothiazépines) ; une sous-unité $\alpha 2$ (140 kDa) qui est liée par des ponts disulfures à $\delta(25 \mathrm{kDa})$; une sous-unité $\beta(55 \mathrm{kDa})$ et une sousunité $\gamma(30 \mathrm{kDa})$. La stœchiométrie est de 1:1:1:1:1 (pour revue [26] et figure 2). Les sous-unités $\alpha 1$ et $\beta$ sont phosphorylées in vitro par la PKA, la PKC, la caséine kinase et la calmoduline kinase, alors que la sous-unité $\alpha 2-\delta$ est une glycoprotéine. La sous-unité $\gamma$ n'a été décrite que pour le muscle squelettique. La purification du récepteur des DHP du tissu cardiaque est beaucoup plus délicate en raison de la densité beaucoup plus faible de sites récep-

teurs, mais l'existence d'une sousunité canalaire $\alpha$ l un peu plus lourde (195 kDa) a aussi été montrée. Ces récepteurs des DHP de type squelettique et cardiaque correspondent bien aux canaux de type L décrits sur ces préparations. La purification du type $\mathrm{N}$ a été possible grâce à l'w-conotoxine d'où le nom initial de "récepteur de l' $\omega$-conotoxine ". La sous-unité $\alpha 1$ aurait un poids moléculaire de 210 à $240 \mathrm{kD}$ et serait phosphorylée in vitro par la PKA et la PKC [27]. Les divers types de canaux calciques sont probablement formés de l'association d'une sous-unité $\alpha$ l avec des sous-unités $\alpha 2$ et $\beta$ apparentées à celle du muscle squelettique. Il a été montré en effet que des anticorps monoclonaux dirigés contre les sous-unités $\alpha 2$ et $\beta$ du canal calcique immunoprécipitent les sites de liaison à la fois aux DHP et à l'w-CgT-GVIA [28]. Une étude

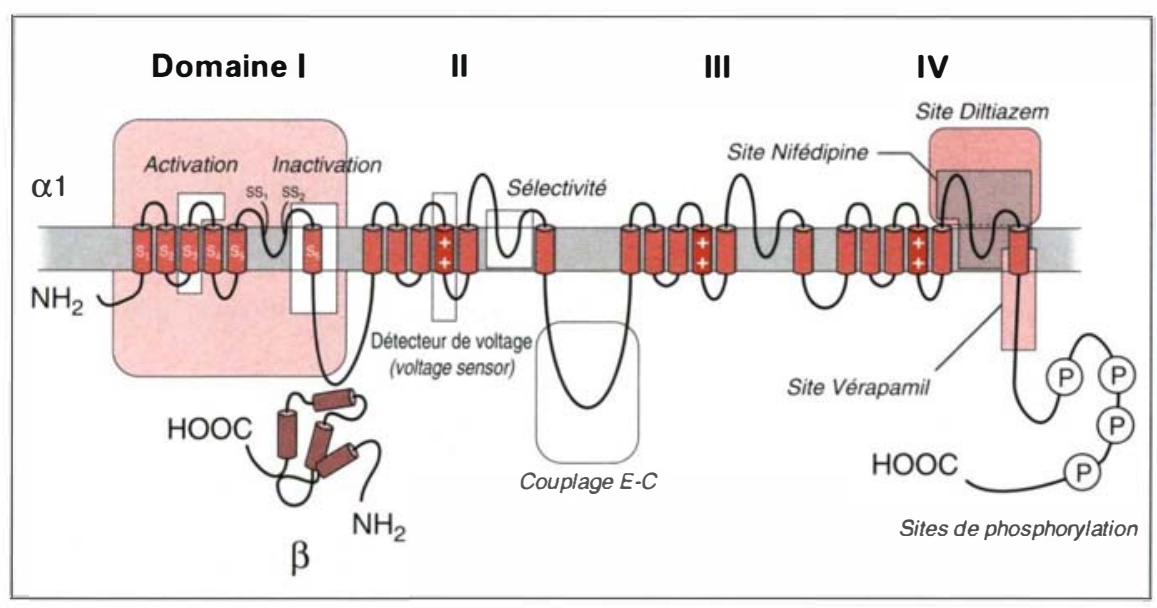

Figure 3. Cartographie fonctionnelle de la sous-unité $\alpha 1$. L'obtention de mutations ponctuelles ou de canaux chimères réalisés à partir des différentes sousunités $\alpha 1$ clonées a permis de localiser certaines séquences importantes pour le fonctionnement normal du canal. Le détecteur de voltage (voltage sensor, partie responsable de l'activation) a ainsi pu être identifié comme le quatrième segment de chaque domaine (S4). De même, les séquences responsables de l'activation et de l'inactivation rapide des types $L$ et $P$ ont été partiellement caractérisées. Des séquences nécessaires pour la fixation des dihydropyridines (nifédipine), des benzothiazépines (diltiazem) et des phénylalkylamines (vérapamil) ont aussi été localisées. Les domaines d'interaction avec la sous-unité $\beta$ sont situés sur la boucle entre les domaines I et II: un motif d'acides aminés commun aux sous-unités $\alpha 1$ (-QQ-E--L-GY--WI--E) interagit avec la séquence 215-255 de la sous-unité $\beta$. La structure responsable du couplage excitationcontraction (couplage $E-C$ ) de type squelettique (via le recepteur de la ryanodine) est située sur $\alpha 1 S$ au niveau de la boucle qui relie les domaines II et III. Enfin, l'analyse de la structure primaire indique que les sites présomptifs pour les phosphorylations dépendantes de la protéine kinase $A$ sont plutôt situés sur la partie carboxyterminale de la protéine. Code à une lettre des acides

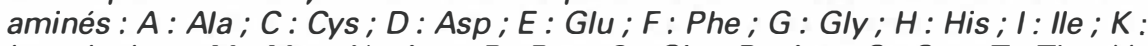

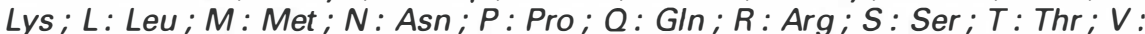
Val $; W: T r p ; Y: T y r$. 


\begin{tabular}{|c|c|l|l|l|l|}
\hline \multicolumn{5}{|c|}{ CARACTÉRISATION DES DIFFÉRENTS GĖNES CODANT POUR LES CANAUX CALCIQUES } \\
ET CORRESPONDANCE FONCTIONNELLE
\end{tabular}

* : classifications établies par les groupes de Snutch (classes S, A, B, C, D, et E) et Perez-Reyes (CaCh1-6).

$S$ : nouvelle appellation du gène codant pour le canal calcique du muscle squelettique.

récente a montré l'association d'un type défini de sous-unité $\beta(\beta 3)$ avec la sous-unité $\alpha$ de type $N$ [27].

\section{Structure primaire des sous-unités des canaux calciques}

\section{Diversité de la sous-unité $\alpha 1$}

Après la purification du récepteur des DHP à partir de muscle squelettique, l'ADNc codant pour la sousunité $\alpha$ l a été cloné par le groupe de Numa au Japon [29]. Les ADNc codant pour des sous-unités $\alpha \mathrm{l}$ ont ensuite été clonés par homologie, à partir de divers tissus, tout d'abord ceux codant pour des sous-unités correspondant aux canaux de type $\mathrm{L}$ des muscles cardiaque et lisse, puis pour des sous-unités $\alpha$ l spécifiques du tissu nerveux (pour revue voir [30]). Plusieurs classifications ont été établies sur des bases structurales et nous nous limiterons à celle proposée par Snutch qui semble la plus utilisée à l'heure actuelle. Sur le cerveau de rat, les $A D N c$ codant pour cinq sous-unités $\alpha$ l semblant correspondre à toutes les grandes familles de canaux calciques identifiées sur des bases fonctionnelles ont été séquencés. Ces sous-unités $\alpha$ l sont codées par des gènes nommés $S, A$, $\mathrm{B}, \mathrm{C}, \mathrm{D}, \mathrm{E}$ comme indiqué sur le Tableau III [31] correspondant probablement sur le plan fonctionnel aux canaux de type $\mathrm{P}$ (classe $\mathrm{A}$ ), $\mathrm{N}$ (classe B), L (classes S, C et D) et peut-être $\mathrm{T}$ (classe $\mathrm{E}$ ). Comme dans le cas du canal sodique, la sous-unité $\alpha$ l est formée de quatre domaines transmenbranaires eux même organisés en six hélices $\alpha$ transmembranaires (figures 2 et 3). Dans le cas des canaux potassiques, une structure similaire forme le canal, mais elle résulte de l'assemblage de quatre domaines homologues indépendants. Pour tous ces canaux, le quatrième segment transmembranaire de chaque domaine est chargé positivement (S4) et constitue le détecteur de voltage (voltage sensor) c'est-àdire la structure sensible aux variations de potentiel. D'autre part, la boucle peptidique qui relie les segments transmembranaires 5 et 6 (S5-S6) dans chaque domaine est formée de deux feuillets $\beta$ intramembranaires dénommés SS1-SS2, impliqués dans la formation du pore et la sélectivité du canal. Il est à noter que des sites de phosphorylation par la PKA sont localisés princi- palement sur la partie carboxyterminale et entre les domaines II et III selon le type de $\alpha$ l. Des sites consensus de phosphorylation pour d'autres kinases (PKC, calmoduline kinase, caséine kinase) sont aussi répartis sur toute la structure.

La variété des sous-unités $\alpha$ l est accrue par l'existence d'isoformes. Le gène de classe $C$, par exemple, produit trois isoformes codant pour des sous-unités $\alpha$ l de type I. (cardiaque, vasculaire et neuronale). Il reste à déterminer si ces toutes petites différences de structure (93\% à $98 \%$ d'identité de séquence) sont à l'origine des différences fonctionnelles observées entre les canaux calciques exprimés à partir d'un même gène dans les cellules cardiaques, vasculaires ou nerveuses. L'étape suivante a été d'établir des corrélations entre les données électrophysiologiques et pharmacologiques recueillies sur les cellules de divers tissus et les données structurales, afin de tenter d'établir des relations entre la structure et la fonction de la sous-unité $\alpha 1$. Pour cela, il a été nécessaire d'utiliser des modèles de reconstitution permettant d'induire une expression fonctionnelle des diverses sous-unités $\alpha$ l. 
Expression des diverses sous-unités $\alpha$ l dans l'ovocyte de xénope

Le modèle d'expression le plus facile à utiliser et le plus robuste est l'ovocyte de xénope qui est capable d'exprimer des protéines membranaires fonctionnelles après micro-injection d'ARNm ou d'ARN transcrit in vitro à partir d'un ADNc. Des canaux calciques fonctionnels ont été exprimés en premier après injection d'ARN total de cerveau et de cour [32]. Le canal calcique exprimé à partir d'ARN de cerveau de rat est insensible aux DHP et à l'w-Cgt-GVIA et fut de ce fait considéré comme n'appartenant ni au type L ni au type $\mathrm{N}$ [33]. Il fut suggéré par la suite qu'il s'apparentait au type $\mathrm{P}$ puis, plus récemment, au type $Q$ [4]. En revanche, les canaux calciques exprimés à partir d'ARN de cour sont sensibles aux DHP et leurs propriétés électrophysiologiques et leur régulation sont similaires à celles observées sur les myocytes cardiaques [34]. En particulier, une élévation de l'AMPc intracellulaire augmente l'amplitude du courant, de façon comparable à celle observée lors d'une stimulation $\beta$-adrénergique sur les cellules cardiaques [18]. L' injection d'ARN, obtenu in vitro à partir des sous-unités $\alpha$ l cardiaque ou vasculaire, induit aussi l'expression de courants calciques sensibles aux DHP mais insensibles à l'AMPc intracellulaire, indiquant que la régulation de l'activité du canal calcique, ne ne résume pas à la sous-unité $\alpha$ l [35]. Les ARN des sous-unités $\alpha$ l d'origine neuronale sont, eux aussi, capables d'exprimer dans l'ovocyte de xénope des canaux calciques fonctionnels sensibles respectivement aux DHP, à l' $\omega$ CgT-GVIA et à l'w-Aga-IVA [31, 36] et qui semblent donc correspondre aux canaux de type $\mathrm{L}, \mathrm{N}$, et $\mathrm{P}$ ou $\mathrm{Q}$ (quelques exemples sont présentés sur la figure 4). Le courant exprimé à partir du gène de classe E s'apparente le plus au courant de type $T$, dans la mesure où il est activé par de faibles dépolarisations, mais sa cinétique est plus lente que celle du courant $\mathrm{T}$ observée sur des cellules nerveuses [37]. L'absence de ligand vraiment spécifique ne permet pas, à l'heure actuelle, d'affirmer une correspondance entre le produit du gène de classe $\mathrm{E}$ et le canal de type $\mathrm{T}$.

On peut enfin noter que l'utilisation de l'ovocyte de xénope comme modèle de reconstitution de canaux calciques est limitée par certains facteurs : l'existence de canaux calciques endogènes peut contaminer l'étude des canaux d'origine exogène, en particulier lorsque le niveau d'expression est faible ; globalement, seuls les ARN extraits de cerveau et de muscle cardiaque permettent un niveau d'expression convenable ; de plus, la sous-unité $\alpha 1$ de muscle squelettique ne conduit jamais à l'expression de courants calciques après injection d'ARN aussi bien extrait de muscle que transcrit in vitro à partir de l'ADNc.

Expression des sous-unités $\alpha$ l dans des lignées cellulaires de mammifère

Les cellules de mammifères offrent une autre alternative pour les études structure-fonction portant sur les sous-unités $\alpha$ l grâce à deux approches complémentaires. Un modèle de complémentation a, tout d'abord, prouvé que la sous-unité $\alpha 1$ de muscle squelettique est capable de former un canal calcique, même si son rôle sur le muscle squelettique adulte est assimilé à celui d'un voltage sensor qui, par liaison directe aux récepteurs de la ryanodine, permet la libération du calcium stocké dans le réticulum sarcoplasmique. Il s'agit des myotubes en culture de la souris mdg (muscular dysgenesis) sur lesquels la sous-unité $\alpha$ l est absente, ce qui entraîne une disparition à la fois du courant calcique lent, des sites de liaison aux DHP et de la contraction [38]. La micro-injection dans le noyau de l'ADNc codant pour la sous-unité $\alpha$ l de muscle squelettique a permis, sur certains myotubes, de restaurer à la fois le courant calcique lent et la contraction [39]. Les sous-unités auxilliaires étant exprimées normalement, ce modèle est donc extrêmement intéressant pour la comparaison et les études structure-fonction portant sur la sous-unité $\alpha 1$.

Des lignées de cellules de mammifères peuvent aussi être utilisées pour transfecter de façon transitoire un ADNc codant pour une sousunité $\alpha$ l. Cela a été réalisé avec les cellules HEK283, par exemple, pour 


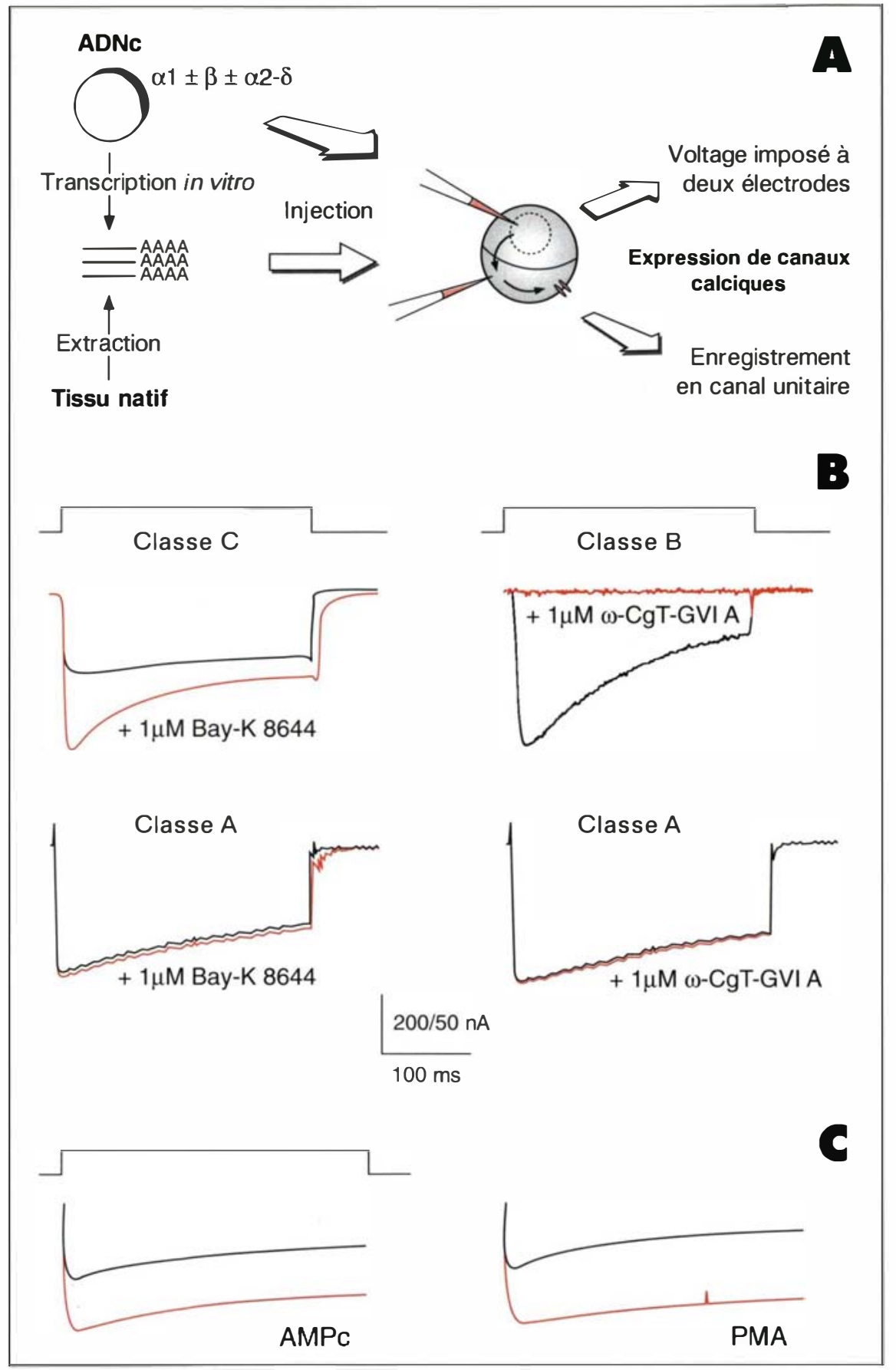

Figure 4. Pharmacologie comparée des trois types de canaux calciques (classes $C, B$, et A). (A). L'injection d'ARN codant pour les différentes sousunités du canal calcique ( $\alpha 1, \beta$ et $\alpha 2 \delta$ ) dans des ovocytes de xénope induit, après deux à trois jours, la formation de canaux présentant des propriétés électrophysiologiques et pharmacologiques similaires à celles mises à jour sur des cellules natives. (B). Le canal de classe $C$ (type $L$ ) est activé par une dihydropyridine (Bay-k 8644), le canal de classe $B$ (type N) est bloqué par I' $\omega$-CgT-GVIA et le canal de classe A (type $Q$ ou P), est insensible à ces deux agents. (C). Après expression dans l'ovocyte de xénope (par injection $d^{\prime} A R N$ de cœur), les courants calciques de type $L$ restent sensibles aux régulations par la protéine kinase $A$ (stimulation par l'AMPc) ou $C$ (stimulation par l'ester de phorbol, PMA). Les courants sont activés par des dépolarisations de $+10 \mathrm{mV}$ à partir d'un potentiel de membrane de $-80 \mathrm{mV}$. la sous-unité $\alpha$ l spécifiant le type $\mathrm{N}$ (classe B) [40]. Les fibroblastes L murins présentent l'avantage d'être le seul modèle qui ne possède pas de canaux calciques endogènes, c'est-à-dire aucune des sous-unités impliquées dans la formation d'un canal calcique. La transfection stable de la sous-unité $\alpha$ l squelettique induit l'apparition d'un courant calcique très lent et sensible aux DHP. Très rapidement, des lignées cellulaires stables exprimant diverses combinaisons de sous-unités ont été établies. Ce modèle est donc particulièrement bien adapté à l'étude du rôle des sous-unités auxiliaires (pour revue [41]). Les cellules $\mathrm{CHO}$ sont aussi utilisées pour réaliser des lignées cellulaires exprimant de façon permanente les sous-unités $\alpha$ l cardiaque ou vasculaire, en présence ou en l'absence de sous-unités auxiliaires [42].

Etudes structure-fonction de la sousunité $\alpha 1$

Ces divers modèles d'expression, transitoire ou stable, ont permis des études structure-fonction portant sur la sous-unité $\alpha 1$. Dans les myotubes $m d g$, la micro-injection des sous-unités $\alpha$ l squelettique et cardiaque induit, respectivement, l'apparition d'un courant calcique avec les caractéristiques du L squelettique (cinétique très lente) ou du $\mathrm{L}$ cardiaque, et un couplage excitation-contraction insensible (type squelettique) ou dépendant (type cardiaque) du calcium extracellulaire [39]. La constitution de chimères entre les sous-unités $\alpha$ l squelettique et cardiaque a montré que la structure responsable du couplage excitationcontraction de type squelettique est la boucle intracellulaire qui relie les domaines II et III [43], et que le domaine I est responsable de la cinétique rapide ou lente de l'activation du courant calcique (plus précisément le segment S3 [44]). Une stratégie similaire, basée sur la constitution de chimères entre une sous-unité $\alpha$ l cardiaque sensible aux DHP (classe C) et une sous-unité $\alpha$ l de type $\mathrm{P}$ (classe $\mathrm{A}$ ), a montré que les sites de fixation des DHP se situent du côté extracellulaire, au niveau des segments SS1-SS2 et S6 du domaine IV [45]. Ces résultats 


\section{RÉFÉRENCES}

44. Nakai J, Adams BA, Imoto K, Beam KG. Critical roles of the S3 segment and S3-S4 linker of repeat $I$ in activation of L-type calcium channels. Proc Natl Acad Sci USA $1993 ; 91: 1014-8$.

45. Tang S, Yatari A, Bahinski A, Mori Y, Schwartz A. Molecular localization of regions in the L-type calcium channel critical for dihydropyridine action. Neuron 1993; 11:1013-21.

46. Catterall WA. Structure and function of voltage-gated ion channels. Trends Neurosci $1993 ; 16: 500-6$.

47. Tang S, Mikala G, Bahinski A, Yatani A, Varadi G, Schwartz A. Molecular localization of ion selectivity sites within the pore of a human L-type cardiac calcium channel. J Biol Chem $1990 ; 268$ : 13026-9.

48. Pragnell M, De Waard M, Mori Y, Tanabe T, Snutch TP, Campbell KP. Calcium channel $\beta$-subunit binds to a conserved motif in the I-II cytoplasmic linker of the $\alpha 1$-subunit. Nature $1994 ; 368$ : 67-70.

49. Ruth P, Rohrkasten A, Biel M, Bosse E, Regulla S, Meyer H.E, Flockerzi V, Hofmann F. Primary structure of the Beta subunit of the DHP-sensitive calcium channel from skeletal muscle. Science 1991 ; $245: 1115-8$.

50. Collin T, Wang IJ, Nargeot J, Schwartz A. Molecular cloning of three isoforms of the L-type voltage-dependent calcium channel Beta subunit from human heart. Circ Res $1993 ; 72: 1337-44$.

51. Collin T, Lory P, Taviaux S, Courtieu C, Guilbault P, Berta P, Nargeot J. Cloning, chromosomal location and functional expression of the human voltage-dependent calcium-channel $\beta 3$ subunit. Eur J Biochem $1994 ; 220: 257-62$.

52. Rosenfeld MR, Wong E, Dalmau J, Manley G, Posner JB, Sher E, Furneaux HM. Cloning and characterisation of a Lambert-Eaton myastenic syndrome antigen. Ann Neurol 1993; 33: 113-20.

53. Lory P, Collin T, Nargeot J. Multiple Ca channel gatings arising from the expression of distinct $\beta$ subunits isoforms in Xeno- précisent ceux obtenus par une approche biochimique qui situaient les sites de fixation des DHP dans la même région et qui ont montré que le site de liaison du vérapamil est du coté intracellulaire, localisé dans la partie carboxyterminale qui suit le segment S6 [46]. La fixation du diltiazem fait intervenir des acides aminés appartenant au SSl du domaine IV. La localisation des structures participant à la formation du pore a été déterminée : les acides aminés impliqués dans la perméation et la sélectivité pour les ions $\mathrm{Ca}^{2+}$ ont été identifiés en comparant les canaux sodiques et calciques dont la structure est globalement similaire mais la sélectivité ionique entièrement différente ; les seules variations de structure entre ces canaux au niveau SSlSS2 se trouvent dans les domaines III et IV où des acides aminés chargés négativement (Glu) sur les canaux calciques sont remplacés par des acides aminés chargés positivement (Lys et Arg) sur les canaux sodiques. Les mutations Lys ${ }^{1422} \rightarrow \mathrm{Glu}$ et Ala ${ }^{1714} \rightarrow$ Glu dans le canal sodique non seulement affectent la fixation de la tétrodotoxine mais transforment un canal perméable aux ions sodium en canal perméable aux ions calcium [46]. Inversement, des études très récentes viennent de montrer que la substitution dans les canaux calciques d'un ou plusieurs de ces Glu dans la partie SSI-SS2 des domaines I, III ou IV par Gly ou Ala altère fortement la perméabilité calcique d'un canal exprimé à partir d'une sous-unité $\alpha 1$ cardiaque humaine dans l'ovocyte de xénope : ce canal chimérique devient alors perméable aux ions sodium tout en conservant sa sensibilité aux DHP [47]. Ces séquences sont comparées sur la figure 5. I a séquence du peptide de la sous-unité $\alpha$ l qui permet l'interaction avec la sous-unité $\beta$ vient d'être localisée au niveau de la boucle intracellulaire reliant les domaines I et II [48]. Toutes ces informations issues des études structure-fonction portant sur la sous-unités $\alpha 1$ sont illustrées sur le schéma de la figure 3.

Modulation de la sous-unité $\alpha$ par les sous-unités auxiliaires

Les sous-unités $\alpha 2-\delta$ et $\beta$ sont probablement associées à la plupart des diverses sous-unités $\alpha$ l alors que la sous-unité $\gamma$ n'a été décrite que pour le muscle squelettique. Sur le plan fonctionnel, c'est la sous-unité $\beta$ qui exerce la plus grande influence et qui contribue probablement le plus à la diversité des canaux calciques. Les paragraphes suivants seront donc consacrés au rôle de la sousunité $\beta$. On peut dire brièvement que la sous-unité $\alpha 2-\delta$ est la plus conservée et que, jusqu'à présent, on n'a caractérisé qu'un seul gène codant pour cette sous-unité engendrant cependant deux isoformes par épissage alternatif. La co-expression de $\alpha 2-\delta$ avec une sous-unité $\alpha$ l augmente l'intensité du courant calcique et il a été suggéré qu'elle pourrait stabiliser la sous-unité $\alpha 1$ dans la membrane [voir 30].

\section{Caractérisation moléculaire des sous- unités $\beta$}

La sous-unité $\beta$ est une protéine cytoplasmique hydrophile associée à $\alpha \mathrm{l}$, dont le gène a été cloné à partir de muscle squelettique de lapin sur la base de séquences peptidiques dérivées de la protéine purifiée [49]. Elle est codée par un gène désigné $\beta 1$. Par analogie, les ADNc correspondant à trois autres gènes ont été clonés $(\beta 2, \beta 3, \beta 4)$. Il n' y a pas de distribution tissulaire qui rappelle celle des sous-unités $\alpha$ l comme l'indique le Tableau $I V$ et on peut noter des différences interespèces intéressantes concernant l'expression des sous-unités $\beta$ au niveau cardiaque. Ainsi, la sous-unité $\beta 2$ est exprimée de façon importante au niveau cardiaque chez le rat ou le lapin alors que nous avons montré que seul le gène $\beta 1 \quad(\beta 1 a, \beta 1 b, \beta 1 c)$ s'exprime au niveau du cœur humain [50]. De plus une sous-unité $\beta 3$, dont le gène a également été cloné au laboratoire à partir de tissu embryonnaire humain, et localisée sur le chromosome 12 (q13), s'exprime au niveau du cerveau et $\mathrm{du}$ muscle lisse mais est totalement absente au niveau cardiaque [51]. A l'heure actuelle, les gènes correspondants à $\beta 2$ et $\beta 4$ n’ont pas été encore décrits chez l'homme. En revanche, un $\mathrm{ADNc}$ codant pour une sous-unité $\beta$ (MysB) proche sur le plan structural de la sous-unité $\beta 2$ a été isolé en criblant une banque de cerveau fotal humain avec des 


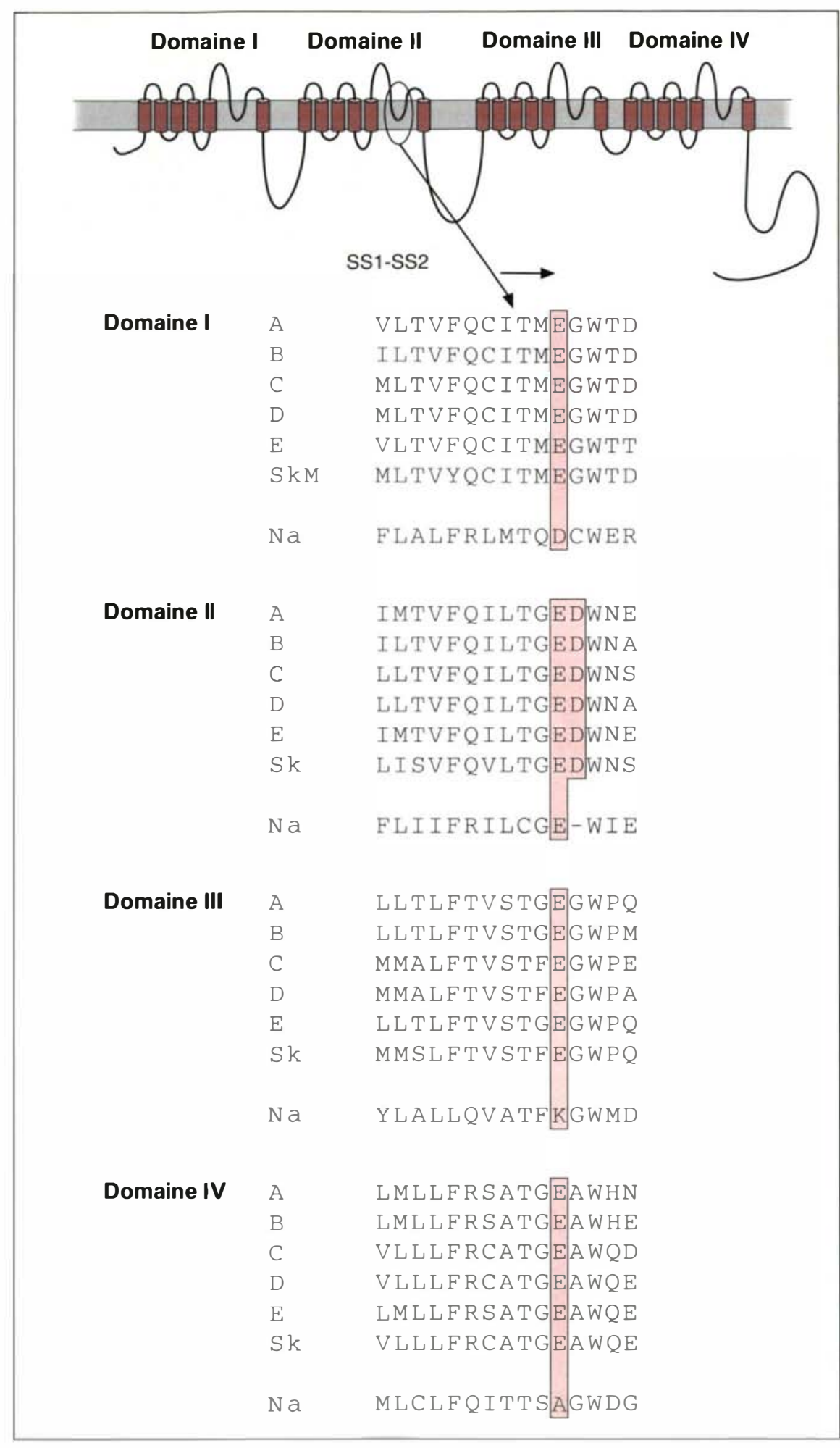

Figure 5. Le pore du canal calcique. Comparaison des séquences correspondant à la structure SS1-SS2 des domaines I, II, III et IV pour les sous-unités $\alpha 1$ de canaux calciques (de classe $A, B, C, D$ et squelettique $S[37,68-71]$ et la sous-unité $\alpha$ d'un canal sodique ( $\mathrm{Na}$ ) type II [71]. sérums de patients atteints du syndrome de Lambert-Eaton [52]. Cette observation quelque peu surprenante (la sous-unité $\beta$ étant cytoplasmique) relance l'intérêt physiopathologique des études des canaux calciques.

Les sous-unités $\beta$ comme véritables modulateurs endogènes des canaux calciques

Les sous-unités $\beta$ jouent un rôle particulièrement important dans la modulation de l'activité "canal calcique" déterminée par la sous-unité $\alpha 1$ et peuvent, en ce sens, être considérées comme de véritables modulateurs endogènes. Il a été montré que la sous-unité $\beta 1$ ( $\beta$ la) augmente fortement l'amplitude des courants calciques exprimés à partir des diverses familles de $\alpha$ l dans l'ovocyte de xénope ou les cellules de mammifères et modifie les propriétés électrophysiologiques et pharmacologiques du canal calcique. C'est la modulation des sous-unités $\alpha$ l de type $L$ qui a été la mieux étudiée. La sous-unité $\beta$ la, coexprimée dans des cellules de mammifère avec la sous-unité $\alpha$ l de muscle squelettique, accélère les cinétiques d'activation et d'inactivation et déplace les courbes courant-potentiel ainsi que la courbe d'inactivation à l'état stable vers les potentiels négatifs. Elle induit aussi une augmentation du nombre de sites de liaison des DHP [41]. Les études d'expression dans l'ovocyte de xénope montrent aussi que la co-expression des autres sousunités $\beta$ augmente l'amplitude des courants exprimés à partir de diverses $\alpha 1$ (figure 6). Cependant, leurs effets sur la cinétique du courant peuvent être différents, la sous-unité $\beta 3$, par exemple, provoquant une forte accélération de l'inactivation contrairement aux isoformes $\beta$ la et $\beta 2$ [53]. Plus précisément, deux isoformes provenant d'un même gène ( $\beta$ la et $\beta$ lb) peuvent avoir des effets opposés sur l'inactivation du courant calcique [53] ce qui indique que l'expression d'isoformes de la sous-unité $\beta$ peut aussi fortement participer à l'apparente diversité fonctionnelle des canaux calciques. 


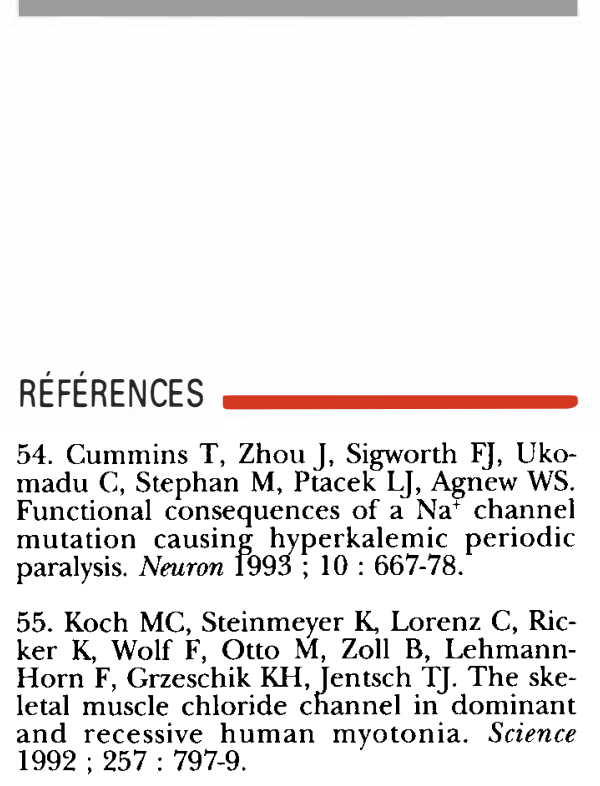

56. Fontaine B, Vale-Santos J, Jurkat-Rott $\mathrm{K}$, Reboul J, Plassart E, Rime CS, Elbaz A, Heine R, Guimaraes J, Weissenbach J, Baumann N, Fardeau M, Lehmann-Horn F. Mapping of the hypokaliemic periodic paralysis (HypoPP) locus to chromosome 1q31-32 in three european families. Nature Genet $1994 ; 6: 267-72$.

57. Corabœuf E, Nargeot J. Electro-physiology of human cardiac cells. Cardiovase Res $1993 ; 27: 1713-25$.

58. Leveque C, Hoshino T, David P, ShojiKasai Y, Leys K, Omori A, Lang B, El Far O, Sato K, Martin-Moutot N, Newson-Davis J, Takahashi M, Seagar MJ. The synaptic vesicle protein synaptotagmin associates with the calcium channels and its putative Lambert-Eaton myasthenic syndrom antigen. Proc Natl Acad Sci USA 1992;89 $3625-9$.

59. Oguro-Okano M, Griesmann GE, Wieben ED, Slaymaker SJ, Snutch TP. Molecular diversity of neuronal-type calcium channels identified in small-cell lung carcinoma. Mayo Clin Proc $1992 ; 67$ : 1-10.

60. Smith RG, Hamilton S, Hofmann F, Schneider T, Nastainczyk W, Birnbaumer L, Stefani E, Appel SH. Serum antibodies to L-type calcium channels in patients with amyotrophic lateral sclerosis. New Engl J Med 1992 ; 327 : 1721-8.

61. Llinas R, Sugimori M, Cherksey BD, Glenn Smith $R$, Delbono $O$, Stefani $E$, Appel S. IgG from amyotrophic lateral sclerosis patients increases current through $\mathrm{P}$ type calcium channels in mammalian cerebellar Purkinje cells and in isolated channel protein in lipid bilayer. Proc Natl Acad Sci USA 1993 ; 90 : 11743-7.

62. Juntti-Berggren L, Larsson $O$, Rorsman P, Ammala C, Bokvist K, Wahlander K, Nicotera P, Dypbukt J, Orrenius S, Hallberg A, Berggren PO. Increased activity of L-type $\mathrm{Ca}^{2+}$ channels exposed to serum from Patients with type I diabetes.

\begin{tabular}{|c|c|c|c|}
\hline \multicolumn{4}{|c|}{ Tableau IV } \\
\hline Gène & GĖNES CODANT POUR LES SOUS-UNITÉS $\beta$ \\
\hline$\beta 1$ & Isoforme & $\begin{array}{r}\text { Expression tissulaire } \\
\text { principale décrite chez } \\
\text { I'animal (rat/lapin) }\end{array}$ & $\begin{array}{c}\text { Association spécifique } \\
\text { décrite avec } \\
\text { une sous-unité } \alpha \text { 1 }\end{array}$ \\
\hline$\beta 2$ & a & $\begin{array}{r}\text { muscle squelettique } \\
\text { cerveau } \\
\text { cerveau }\end{array}$ & \\
\hline$\beta 3$ & a b & $\begin{array}{c}\text { cœur } \\
\text { cerveau } \\
\text { muscle lisse }\end{array}$ & \\
\hline$\beta 4$ & & $\begin{array}{c}\text { cerveau } \\
\text { muscle lisse } \\
\text { cœur }\end{array}$ & \\
\hline & & $\begin{array}{c}\text { cerveau } \\
\text { cervelet }\end{array}$ & \\
\hline
\end{tabular}

La distribution tissulaire des sous-unités $\beta$ n'est pas clairement établie dans la mesure où certaines sondes peu spécifiques ont été utilisées. Elle semble aussi dépendre de l'espèce. Ainsi seul le gène $\beta 1$ paraît être exprimé sur le myocarde humain [50] au lieu du gène $\beta 2$ chez le rat ou le lapin. Des combinaisons spécifiques $(\alpha 1+\beta)$ pourraient exister, ainsi pour le canal de type $L$ du muscle squelettique ( $\alpha 1 \mathrm{~S}$ et $\beta 1 \mathrm{a}$ ) ou le canal du type $N$ dans le cerveau ( $\alpha 1 B$ et $\beta 3$ ). Le gène codant pour MysB, l'antigène révélé par les anticorps contenus dans le sérum des paptients atteints du syndrome de Lambert-Eaton [52], pourrait correspondre au gène $\beta 2$ humain.

\section{Physiopathologie des canaux calciques}

Les données démontrant l'implication de canaux ioniques dans des maladies sont récentes. Elles concernent, par exemple, des canaux sodiques ou des canaux chlorure. Des mutations dans le gène du canal sodique musculaire ont été démontrées dans le cas de la paralysie périodique hyperkaliémique ou de la paramyotonie congénitale $(\mathrm{m} / \mathrm{s}$ $n^{\circ} 1$, vol. 7, p. 79; $n^{\circ} 5$, vol. 8, p. $505)$. Deux mutations trouvées dans le gène et reproduites in vitro ( $\mathrm{Thr}^{704}$ $\rightarrow$ Met et $\mathrm{Met}^{1592} \rightarrow$ Val) provoquent sur le plan fonctionnel à la fois un ralentissement de l'inactivation et un décalage de la courbe courant potentiel pouvant être en relation avec la maladie [54]. Une autre maladie musculaire, la myotonie congénitale, correspond probablement à un dysfonctionnement d'un canal chlorure (m/s $n^{o s} 6 / 7$, vol. 10, $p$. 748) [55].

La variété des gènes codant pour des canaux calciques et l'importance physiologique des processus qu'ils contrôlent, permettent de penser qu'ils sont sans doute impliqués dans la physiopathologie de cer- taines maladies chez l'homme, ce qui n'est pourtant pas clairement établi. Le seul exemple chez l'animal est la souris mdg (muscular dysgenesis) où une mutation du gène qui code pour la sous-unité $\alpha 1$ de muscle squelettique est létale, l'absence de la protéine-canal se traduisant par la disparition du courant calcique lent [38]. On peut penser que des mutations conduisant à une absence de sous-unité $\alpha 1$ ou à une sous-unité $\alpha 1$ non fonctionnelle chez l'homme pourraient aussi être létales. Des maladies liées aux sous-unités associées à $\alpha$ l sont aussi envisageables. Les gènes codant pour des sous-unités $\beta$ qui influencent fortement les propriétés des canaux calciques apparaissent donc comme de bons candidats potentiels responsables de maladies génétiques.

Divers travaux suggèrent à l'heure actuelle que des canaux calciques seraient impliqués dans certaines maladies, avec des modifications de l'expression de canaux calciques, d'éventuelles mutations dans un gène codant pour une sous-unité d'un canal calcique et les canaux calciques comme cible d'anticorps dans des maladies à composante auto-immune. 


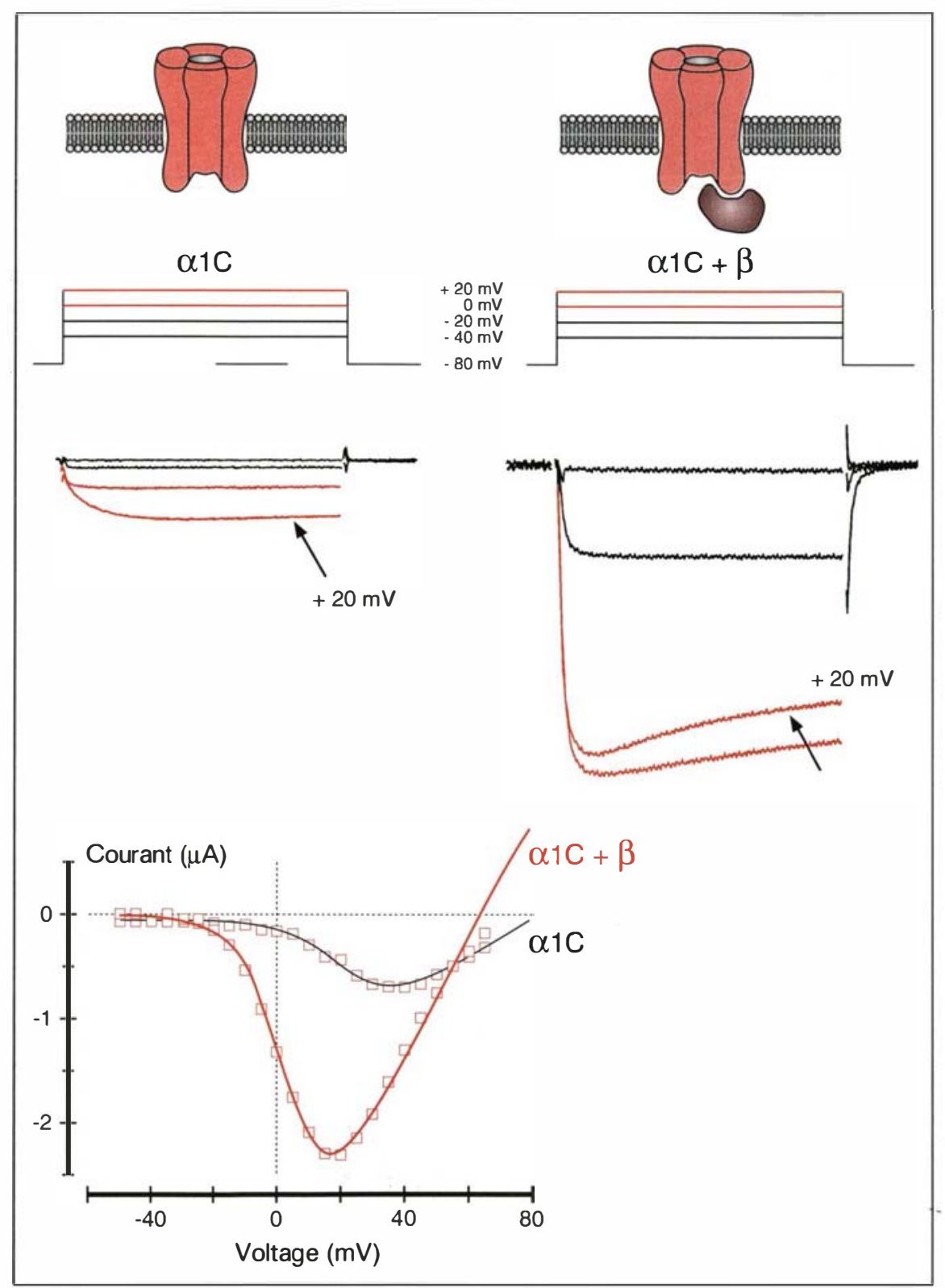

Figure 6 : Modulation des propriétés électrophysiologiques de la sous-unité $\alpha 1 C$ par la sous-unité $\beta$. Courants calciques enregistrés après injection dans des ovocytes de xénope des ADNc codant pour la sous-unité $\alpha 1$ (classe $C$ ) ou $\alpha 1+\beta$. La co-injection de la sous-unité $\beta$ augmente l'amplitude du courant, accélère les cinétiques d'activation et déplace le pic de la courbe courant-potentiel d'environ $20 \mathrm{mV}$ dans le sens des hyperpolarisations. Les courants présentés sont enregistrés pour des dépolarisations de $-40,-20$, 0 et $+20 \mathrm{mV}$ (marqués par une flèche) à partir d'un potentiel de membrane de $-80 \mathrm{mV}$.

$\mathrm{m} / \mathrm{s} n^{\circ} 12$, vol. 10 , décembre 94
Canaux calciques et pathologie musculaire

Un travail très récent suggère que le gène codant pour la sous-unité $\alpha 1$ de muscle squelettique pourrait être impliqué dans une maladie musculaire, la paralysie périodique hypokaliémique $\left(\mathrm{m} / \mathrm{s} n^{o s} 6 / 7\right.$, vol. $\left.10, p .748\right)$ [56]. En effet, une analyse de liaison dans trois familles d'origine géographique très différente a montré que le locus $(H y p o P P)$ de cette maladie se situe sur le chromosome 1q31-32. Le gène codant pour la sous-unité $\alpha 1$ de muscle squelettique qui se situe dans la même région et coségrège avec $H y p o P P$ apparaît donc comme un candidat possible pour cette maladie*.

Dans certaines maladies cardiovasculaires, des modifications de l'amplitude du courant calcique ont été décrites. C'est le cas, par exemple, des cardiomyopathies dilatées humaines où une diminution notable de l'amplitude du courant calcique de type $L$ a été observée [57]. Dans des affections vasculaires, comme l'athérosclérose ou la resténose, se produisent des changements du phénotype cellulaire qui évolue de contractile à synthétique/migratoire selon des critères bien définis. Cette conversion phénotypique est aussi observée au niveau des cellules musculaires lisses en culture et s'accompagne de modifications de l'expression de certains sous-types de canaux calciques. En particulier, il existe une corrélation entre l'expression du courant de type $\mathrm{T}$ et la période où les cellules prolifèrent [10]. Ces observations peuvent servir de base, soit pour établir une relation entre une maladie et des modifications de l'expression de gènes codant pour des canaux calciques, soit pour proposer une sous-unité de canal calcique comme gène candidat dans une affection donnée.

Implication de canaux calciques dans certaines maladies autoimmunes

Plusieurs études suggèrent l'implication des canaux calciques dans certaines maladies à composante autoimmune. Chez des patients qui développent un cancer bronchique à petites cellules, l'expression d'anti-

* La mutation sur la sous-unité $\alpha 1$ a été confirmée récemment C. Placèk et al., Cell 1994: 77 : 863-8. 


\section{RÉFÉRENCES}

63. Hell JW, Westenbroek RE, Warner C, Ahlijanian MK, Prystay W, Gilbert MM, Snutch TP, Catterall WA. Identification and differential subcellular localisation of the neuronal class $C$ and class D L-type calcium channel alpha-1 subunits. $J$ Cell Biol 1993 ; 123 : 949-62.

64. Miyakawa $H$, Ross WN, Jaffe D, Callaway JC, Lasser-Ross N, Lisman JE, Johnston D. Synaptically activated increases in $\mathrm{Ca}^{2+}$ concentration in hippocampal CAl pyramidal cells are primarily due to voltage-gated dal cells are primarily due to voltage-gated
$\mathrm{Ca}^{2+}$ channels. Neuron $1992 ; 9: 1163-73$.

65. Bourinet E, Charnet P, Tomlinson J, Stea A, Snutch TP, Nargeot J. Voltagedependent facilitation of a neuronal $\alpha 1 \mathrm{c} L$ type calcium channel. EMBO J 1994; 13 : $5032-9$.

66. Choi DW. Calcium-mediated neurotoxicity : relationship to specific channel types and role in ischemic damage. Trends Neurosi 1988 ; 11 : 465-9.

67. Valentino $K$, Newcomb $R$, Gadbois $T$, Singh T, Bowersox S, Bitner S, Justice A, Yamashiro D, Hoffman BB, Ciaranello R, Miljanich G, Ramachandran J. A selective $\mathrm{N}$-type calcium channel antagonist protects against neuronal loss after global cerebral against neuronal loss after global cerebral 7894-7.

68. Mori Y, Friedrich T, Kim MS, Mikami A Nakai J, Ruth P, Bosse E, Hofmann F, Flockerzi V, Furuichi T, Mikoshiba K, Imoto K Tanabe T, Numa S. Primary structure and functional expression from complementary DNA of a brain calcium channel. Nature $1991 ; 350: 398-402$.

69. Dubel SJ, Starr TVB, Hell J, Ahlijanian MK, Enyeart IJ, Catterall WA, Snutch TP. Molecular cloning of the $\alpha-1$ subunit of an w-conotoxin-sensitive calcium channel. Proc Nall Acad Sci USA 1992;89 5058-62.

70. Snutch TP, Tomlinson WJ, Leonard JP, Gilbert MM. Distinct calcium channels are generated by alternative splicing and are differentially expressed in the mammalian CNS. Neuron $1991 ; 7: 45-57$.

71. Williams ME, Feldman DH, McCue AF, Brenner R, Velicelebi $G$, Ellis SB Harpold MM. Structure and functional expression of $\alpha-1, \alpha-2$ and $\beta$ subunits of a novel human neuronal calcium channel subtype. Neuron $1992 ; 8: 71-84$

72. Noda M, Ikeda T, Kayano T, Suzuki M, Takesmira H, Kurasaki M, Takahashi $\mathbf{H}$, Numa S. Existence of distinct sodium channel messenger RNAs in rat brain. Nature $1993 ; 320: 188-92$ gènes à caractère neuronal par la tumeur induit la production d'anticorps dirigés, entre autres, contre des canaux calciques neuronaux. Ces anticorps pourraient reconnaître et bloquer les canaux calciques apparentés dans d'autres tissus. A la jonction neuromusculaire, la réduction de la libération d'acétylcholine qui est contrôlée par des canaux calciques présynaptiques, serait à l'origine de la faiblesse musculaire cliniquement définie comme le syndrome de Lambert-Eaton ou LEMS. L'exocytose d'un neurotransmetteur dans le système nerveux central pourrait en fait impliquer un complexe de plusieurs protéines associées comprenant le canal calcique de type $\mathrm{N}$ (sensible à l' $\omega$-CgT-GVIA), la synaptotagmine et la syntaxine $(\mathrm{m} / \mathrm{s} n$ os $8-9$, vol. $9, p .1000)$. Il a été montré que toutes ces protéines sont bien coexprimées dans des lignées établies à partir de cellules du cancer du poumon, l'antigène reconnu par les anticorps LEMS semblant être la synaptotagmine [58]. Cependant, des données récentes suggèrent aussi l'implication d'un autre canal calcique, le canal de type $\mathrm{P}$ (classe $\mathrm{A}$ ) qui a pu être cloné sur les mêmes lignées cellulaires issues de cancer du poumon à petites cellules [59]. Un argument en faveur de cette hypothèse est que le LEMS s'accompagne parfois de dégénéresence du cervelet où le canal calcique de type $P$ est fortement exprimé. De plus, il a été démontré que le canal de type $P$ contrôle la libération d'acétylcholine à la jonction neuromusculaire de mammifère, ce qui renforce encore cette hypothèse [8]. Une autre équipe, utilisant des sérums de patients LEMS pour cribler une banque de cerveau fœtal humain, a isolé un ADNc codant pour une protéine (MysB) très proche sur le plan structural de la sous-unité $\beta 2$ du canal calcique [52]. Si l'on considère l'ensemble de ces données, on peut imaginer que la tumeur expose au système immunitaire plusieurs types de protéines, incluant des sous-unités de canaux calciques, et que les anticorps dirigés contre ces canaux ont les conséquences fonctionnelles les plus importantes.

Une autre maladie décrite comme impliquant des canaux calciques et qui a pour conséquence une paraly- sie musculaire est la sclérose latérale amyotrophique (SLA). Cette affection caractérisée par la dégénéresence du motoneurone semble liée à l'action d'immunoglobulines ayant pour cible des canaux calciques. A l'inverse des LEMS, c'est l'entrée accrue de calcium qui paraît responsable de la mort du motoneurone. Ces sérums SLA réduisent l'amplitude de canaux calciques musculaires [60]. Cela ne va pas dans le sens attendu mais il faut noter que ces canaux musculaires ne sont pas ceux concernés par la maladie. Il est intéressant de noter que des expériences plus récentes du même groupe viennent de montrer que ces IgG de patients atteints de SLA ont une action opposée sur les canaux de type $\mathrm{P}$ présents sur les motoneurones où ils augmentent l'amplitude du courant. L'augmentation de l'influx calcique par ce biais pourrait donc contribuer à la neurotoxicité [61].

Enfin, une autre maladie à composante auto-immune, le diabète de type I, semble concerner des canaux calciques. On peut faire le parallèle avec le mécanisme décrit pour la SLA puisque l'augmentation de l'activité de canaux calciques de type $\mathrm{L}$, démontrée sur une lignée pancréatique en présence du sérum de ces malades, induirait une surcharge calcique considérée comme responsable de la destruction des cellules $\beta$ du pancréas [62].

On peut dire en conclusion que les études concernant la physiopathologie des canaux calciques ne font que commencer et que les approches génétiques ainsi que la possibilité d'exprimer une catégorie bien définie de canal dans un modèle de reconstitution devrait permettre dans le futur d'établir des corrélations entre le dysfonctionnement d'un canal calcique donné et une maladie.

\section{Conclusion : enjeux thérapeutiques}

Les canaux calciques ont suscité depuis longtemps un grand intérêt sur le plan de la thérapeutique cardiovasculaire, la sous-unité $\alpha 1$ du type L étant la cible directe des diverses familles "d'antagonistes calciques" utilisées en clinique dans le 
traitement de l'hypertension ou la protection du myocarde. En bloquant partiellement le pore, ces molécules réduisent l'influx calcique, abaissent la tension artérielle et protègent la cellule cardiaque. Les approches structurales et fonctionnelles sont importantes pour améliorer la spécificité tissulaire des antagonistes calciques. La plupart des antagonistes calciques disponibles en clinique sont destinés à la thérapeutique cardiovasculaire et ont pour cible le canal de type L. Les mécanismes de sélectivité tissulaire sont en partie assurés par le fait que les différentes classes d'antagonistes calciques ont une action qui dépend, soit de la fréquence des stimulations, soit du potentiel membranaire, propriétés souvent décrites en terme de use et voltage dependence. Le gène de classe $\mathrm{C}$ engendre, probablement par épissage alternatif, les isof ormes cardiaque, vasculaire et neuronale. Les canaux de type L sont présents dans le système nerveux central au niveau des corps cellulaires et des dendrites proximaux, notamment dans les neurones CAl de l'hippocampe [63]. Ils pourraient donc participer à l'élévation du calcium intracellulaire impliquée dans l'activation de certains processus physiologiques ou, dans d'autres cas, à l'induction d'une surcharge calcique qui est caractéristique de nombreuses situations pathologiques. La potentiation à long terme (long term potentiation, LTP) induite in vitro par des trains de stimuli est considérée comme un processus élémentaire impliqué dans l'établissement de la mémoire. Elle serait liée en particulier à une élévation du calcium intracellulaire sous la dépendance des récepteurs du glutamate et en particulier du récepteur NMDA. Cependant, certaines formes de LTP indépendantes du récepteur NMDA ont été décrites et sont probablement induites par un ou plusieurs types de canaux calciques neuro- naux pré- ou post-synaptiques [4, 64]. De fortes pré-dépolarisations ou bien une salve de stimulations répétitives sont capables d'induire une grande augmentation de l'entrée de calcium par le canal calcique lors de la dépolarisation suivante. Ce processus décrit sous le terme de "facilitation" a été observé, en particulier, pour les canaux de type $L$ de diverses cellules, ce type de régulation pouvant être impliqué au niveau des neurones dans l'initiation de la LTP. Nous avons montré récemment que cette facilitation peut être reproduite in vitro dans l'ovocyte de xénope à la suite de la co-expression d'une sous-unité $\alpha$ l neuronale de type $L$ avec les sousunités auxiliaires $\alpha 2$ et $\beta$ ( $\beta 1 \mathrm{~b}$ ) d'origine nerveuse. Plusieurs éléments importants et nouveaux ont été révélés. Ce processus de facilitation requiert, d'une part, un certain degré de phosphorylation par la protéine kinase A et, d'autre part, la présence de la sous-unité $\beta$. De plus, la facilitation n'est pas observée avec les autres sous-unités $\alpha$ l neuronales (gènes de classe $A, B$ ou E). Ces résultats mettent en évidence pour la première fois une régulation différentielle des sous-unités $\alpha$ l de type neuronal et le rôle possible d'une sous-unité $\beta$ dans un mécanisme moléculaire pouvant intervenir dans l'établissement d'une fonction physiologique intégrée [65]. Il est à présent nécessaire de comparer les effets des différentes isof ormes de $\beta$ sur la facilitation du canal calcique. Lors d'une ischémie cérébrale, l'entrée massive d'ions $\mathrm{Ca}^{2+}$ active des phospholipases ou des protéases qui vont détruire les neurones, les plus sensibles étant ceux de la région CAl de l'hippocampe. L'ischémie cérébrale, bien que mettant en jeu de nombreux paramètres influencés par la chute de l'ATP et l'acidose, est caractérisée, entre autres, par une dépolarisation membranaire [66]. Les canaux de type L post-synaptiques apparaissent donc, au même titre que le récepteur NMDA, comme des cibles pharmacologiques potentielles pour prévenir l'influx calcique. Si les antagonistes calciques ont, à l'heure actuelle, une efficacité limitée voire même controversée dans une telle indication, il est probable que cela est dû en partie à leur manque de spécificité entre les isoformes neuronale, cardiaque ou vasculaire. L'ischémie cérébrale s'accompagne aussi d'une forte élévation de la concentration de glutamate, dont la libération est contrôlée par des canaux calciques présynaptiques de type $\mathrm{N}$ et $\mathrm{P}[6,7]$. Des travaux très récents viennent d'ailleurs de montrer qu'un peptide synthétique dérivé de l'w-CgT-GVIA est capable de protéger des neurones pyramidaux de la région $\mathrm{CAl}$ de l'hippocampe dans un modèle expérimental d'ischémie cérébrale globale chez le rat, la neuroprotection se prolongeant plus de $24 \mathrm{~h}$ après l'accident ischémique [67]. Ces données, considérées dans leur ensemble, montrent à quel point il est nécessaire de comprendre la diversité des canaux calciques afin de proposer des stratégies pour le développement de nouvelles molécules d'intérêt thérapeutique

\section{Remerciements}

Les travaux de notre laboratoire présentés dans ce manuscrit ont été réalisés avec le soutien de l'Association Française contre les Myopathies et de l'OTAN (CRG-890374). Nous remercions également tous les membres de l'équipe et en particulier Philippe Lory, Sylvain Richard, Emmanuel Bourinet et Thibault Collin pour leur participation à l'illustration du manuscrit et leurs commentaires sur sa présentation et son contenu. 


\section{Summary}

Molecular diversity of calcium channels : from gene to function

Recent studies have revealed the molecular and functional diversity of voltage-gated calcium channels. Electrophysiological and pharmacological experiments on various cell types have provided a way of characterizing a Low Voltage Activated (LVA) or "T-type ", and several High Voltage Activated (HVA) calcium channels. LVA $\mathrm{Ca}^{2+}$ channels have fast kinetics and no specific ligands while $\mathrm{HVA} \mathrm{Ca}^{2+}$ channels have been identified mainly by the use of specific toxins, and named $L$, $\mathrm{N}, \mathrm{P}$ and $\mathrm{Q}$. They are blocked by dihydropyridines, $\omega-\mathrm{CgT}-\mathrm{GVIA}, \omega-$ Aga-IVA and $\omega$-CmT-MVIIC, respectively. Biochemical studies have revealed that skeletal muscle $\mathrm{Ca}^{2+}$ channels are composed of a poreforming $\alpha$ l subunit and several asso- ciated subunits $(\alpha 2-\delta, \beta$ and $\gamma)$. Several $\alpha$ l subunits have been cloned from various tissues and are encoded by at least six genes. Their expression in Xenopus oocytes or in mammalian cells induces calcium channel currents, the properties of which seem to correspond to the different $\mathrm{Ca}^{2+}$ channels identified in various cells. However, it has been suggested that further diversity may be provided by the addition of auxiliary subunits and particularly the $\beta$ subunits which are thought to be associated to most of the $\alpha$ l subunits. $\beta$ subunits encoded by at least four genes $(\beta 1, \beta 2, \beta 3, \beta 4)$ expressed in the nervous system and other tissues enhance $\mathrm{Ca}^{2+}$ channel activity and are able to modify both electrophysiological and pharmacological properties. However, a differential effect on calcium current inactivation has been observed between the different isof orms $(\beta 1, \beta 2, \beta 3)$ and their splice variants $(\beta l a, \beta$ lb) indicating that multiple $\mathrm{Ca}^{2+}$ channel gating may arise from the expression of different subtypes of $\beta$ subunits. The implication of $\mathrm{Ca}^{2+}$ channels in pathophysiology has been recently suggested and the genes coding for $\alpha$ l or $\beta$ subunits are potential candidates in some pathologies. Several autoimmune diseases have also been suggested to involve $\mathrm{Ca}^{2+}$ channels as the targets for antibodies. Moreover, the functional diversity of neuronal $\mathrm{Ca}^{2+}$ channel offers new perspectives in the development of drugs for the treatment of neurologic disorders. 